\title{
Simultaneous Identification and Quantification of Three Biologically Active Xanthones in Garcinia Species Using a Rapid UHPLC-PDA Method
}

\author{
Azazahemad A. Kureshi ${ }^{1,10}$, Chirag Dholakiya ${ }^{2}$, Tabaruk Hussain ${ }^{3}$, Amit Mirgal ${ }^{4}$, Siddhesh P. Salvi ${ }^{5}$, \\ Pritam C. Barua ${ }^{6}$, Madhumita Talukdar ${ }^{6}$, C. Beena ${ }^{7}$, Ashish Kar ${ }^{8}$, T. John Zachariah', \\ Premlata Kumari $^{1}$, Tushar Dhanani ${ }^{10}$, Raghuraj Singh ${ }^{10}$ and Satyanshu Kumar ${ }^{10^{*}}$ \\ 'Deparment of Applied Chemistry, SVNIT, Surat, Gujarat, India \\ 2Waters (India) Pvt Ltd., S.G. Highway, Ahmedabad-380015, Gujarat, India \\ SCSCA, Assam Agricutural University, Dhubri, Assam, India \\ ${ }^{4}$ Gogate Joglekar College, Ratnagiri-415612, Maharashtra, India \\ ${ }^{5}$ Regional Fruit Reseach Station, Vengurla-416516, Maharashtra, India \\ Assam Agricutural University, Jorhat, Assam, India \\ Kerala Agricultural University, Thrissur, Kerala, India \\ ${ }^{8}$ The Energy and Resources Institute (TERI), North Eastern Regional Centre, Guwahati-781036, Assam, India \\ ICAR-Indian Institute of Spices Research, Calicut-673012, Kerala, India \\ ${ }^{10}$ ICAR-Directorate of Medicinal and Aromatic Plants Research, Anand-387310, Gujarat, India
}

Received: 22 April 2019; accepted: 16 July 2019

\begin{abstract}
Xanthones are well recognized as chemotaxonomic markers for the plants belonging to the genus Garcinia. Xanthones have many interesting pharmacological properties. Efficient extraction and rapid liquid chromatography methods are essentially required for qualitative and quantitative determination of xanthones in their natural sources. In the present investigation, fruit rinds extracts of 8 Garcinia species from India, were prepared with solvents of varying polarity. Identification and quantification of 3 xanthones, namely, $\alpha$-mangostin, $\beta$-mangostin, and $\gamma$-mangostin in these extracts were carried out using a rapid and validated ultra-high-performance liquid chromatographyphotodiode array detection (UHPLC-PDA) method at $254 \mathrm{~nm} . \gamma$-Mangostin $(3.97 \pm 0.05 \mathrm{~min})$ was first eluted, and it was followed by $\alpha$-mangostin $(4.68 \pm 0.03 \mathrm{~min})$ and $\beta$-mangostin $(5.60 \pm 0.04 \mathrm{~min})$. The calibration curve for $\alpha$-mangostin, $\beta$-mangostin, and $\gamma$ - mangostin was linear in the concentration range $0.781-100 \mu \mathrm{g} / \mathrm{mL}$. $\alpha$-Mangostin was quantified in all 4 extracts of Garcinia mangostana. Its content (\%) in hexane, chloroform, ethyl acetate, and methanol extracts of $G$. mangostana was $10.36 \pm 0.10,4.88 \pm 0.01,3.98 \pm 0.004$, and $0.044 \pm 0.002$, respectively. However, the content of $\alpha$-mangostin was below the limit of detection or limit of quantification in the extracts of other Garcinia species. Similarly, $\beta$-mangostin was quantified only in hexane $(1.17 \pm 0.01 \%)$, chloroform $(0.39 \pm 0.07 \%)$, and ethyl acetate $(0.28 \pm 0.03 \%)$ extracts of $G$. mangostana. $\gamma$-Mangostin was quantified in all 4 extracts of G. mangostana. Its content (\%) in hexane, chloroform, ethyl acetate, and methanol extracts of G. mangostana was $0.84 \pm 0.01,1.04 \pm 0.01,0.63 \pm 0.04$, and $0.15 \pm 0.01$, respectively. $\gamma$-Mangostin was also quantified in hexane $(0.09 \pm 0.01)$, chloroform $(0.05 \pm 0.01)$, and ethyl acetate $(0.03 \pm 0.01)$ extracts of $G$. cowa, ethyl acetate extract of $G$. cambogia $(0.02 \pm 0.01)$, G. indica $(0.03 \pm 0.01)$, and G. loniceroides $(0.07 \pm 0.01)$. Similarly, $\gamma$-mangostin was quantified in 3 extracts of $G$. morella, namely, hexane $(0.03 \pm 0.01)$, chloroform $(0.04 \pm 0.01)$, and methanol $(0.03 \pm 0.01)$. In the case of $G$. xanthochymus, $\gamma$-mangostin was quantified in chloroform $(0.03 \pm 0.001)$ extract only. $\alpha$-Mangostin and $\beta$-mangostin were not detected in any of 4 extracts of $G$. pedunculata.
\end{abstract}

Keywords: $\alpha$-mangostin, $\beta$-mangostin, $\gamma$-mangostin, Garcinia

\section{Introduction}

Ethnomedically, different parts of Garcinia plants have been reported to exhibit many pharmacological effects. Fruits of most species in this genus are edible and are used frequently as food [1]. The nonedible pericarp of Garcinia species is used in traditional medicines to treat wounds, ulcers, dysentery, etc. [2]. There are numerous therapeutic claims based on a long tradition of use. In order to validate/develop evidencebased claims, which would increase the benefits of local knowledge system to a wider population, qualitative and quantitative analyses of the classes of compounds responsible for biological activities is required.

\footnotetext{
* Author for correspondence. E-mail: satyanshu66@gmail.com.
}

More than 200 xanthones are currently known to exist in nature [3]. Xanthones are well recognized as chemotaxonomic markers for the plants of Garcinia species. Garcinia species are important sources of xanthones, and 74 species comprising more than half of all the Garcinia species studied so far were reported to contain xanthones. Xanthone is a class of polyphenolic compounds with a skeleton of a xanthone-9-one. Xanthones contain a distinctive tricyclic aromatic ring system; most often these rings are substituted with a variety of isoprene, phenolic, and methoxy groups, thereby giving rise to a large variety of possible structures [4]. Along with other xanthone types of compounds garcinone $\mathrm{E}$ and gartanin, three xanthones, namely, $\alpha$-mangostin (LM), $\beta$ mangostin (BM), and $\gamma$-mangostin (YM), exhibit potential chemopreventive and chemoprotective properties that have

This is an open-access article distributed under the terms of the Creative Commons Attribution-NonCommercial 4.0 International License (https://creativecommons.org/licenses/by-nc/4.0/), which permits unrestricted use, distribution, and reproduction in any medium for non-commercial purposes, provided the original author and source are credited, a link to the CC License is provided, and changes - if any - are indicated. 
<smiles>COc1c(O)cc2oc3cc(O)c(CC=C(C)C)c(O)c3c(=O)c2c1CC=C(C)C</smiles>

(a)<smiles>COc1cc2oc3cc(O)c(OC)c(CC=C(C)C)c3c(=O)c2c(O)c1CC=C(C)C</smiles>

(b)<smiles>CC(C)=CCc1c(O)cc2oc3cc(O)c(O)c(CC=C(C)C)c3c(=O)c2c1O</smiles>

(c)

Figure 1. Chemical structures of (a) LM, (b) BM, and (c) YM

been extensively investigated for their inhibitory effect on every step of the carcinogenesis process. These compounds can inhibit several molecular targets in the tumor cells including kinases, cyclooxygenases (COX), ribonucleotide reductase, and DNA polymerases [5-7]. The antitumor activities of xanthones include cell cycle arrest, suppression of tumor cell, proliferation, induction of apoptosis and differentiation, reduction of inflammation, inhibition of adhesion, invasion, and metastasis [8]. LM, BM, (Figure 1a, b) and garcinone exhibited strong inhibitory effect against Mycobacterium tuberculosis. YM (Figure 1c) directly binds to COX and inhibits its activity. This effect of YM may contribute to its anti-inflammatory activity. It selectively inhibited both the COX-1 and COX-2, and the drug seems to be similar to indomethacin in terms of its selectivity towards to COX. It is an attractive drug because its analogs of tetraoxygenated diprenylated xanthones are contained in many plants, vegetables, and fruits [7]. Biological activities exhibited by naturally occurring xanthones have increased the interest and demand for nutritional supplement products containing these ingredients [4].

G. cambogia popularly known as "Malabar Tamarind" is distributed throughout the world. Traditionally, it is used as a condiment and a curing agent in meat and fish curries. It has a commercial value because of wide applications of its fruit rinds [9]. Different parts of G. cowa have been used in Thai folk medicine for various purposes [10]. G. cowa has been a rich source of many phytochemicals including xanthones [10-14]. More than 86 compounds including LM and BM were reported from twigs, stems, fruits, and latex of $G$. cowa [15]. G. indica has been identified as an important plant for promotion and development by the National Medicinal Plant Board, New Delhi, India. Polyisoprenylated benzophenones (PIBs) are the major secondary metabolites reported from $G$. indica. Xanthones and biflavanols were also reported from $G$. indica [16]. G. loniceroides is an evergreen shrub or a small tree. It is distributed in the Nagaland and Manipur states of India [17]. Scientific study on this lesser known species from Garcinia is almost missing in the literature. Different parts of G. mangostana, mostly fruit hull, bark, and roots, have been used in Southeast Asia as a medicine for a wide variety of medical conditions since hundreds of year ago. G. mangostana has also found its medicinal use in $\mathrm{Ca}-$ ribbean and Latin America [18]. The major bioactive secondary metabolites of $G$. mangostana are xanthone derivatives $[19,20]$. Although, more than 60 xanthones were isolated from different parts of G. mangostana, LM and YM were found to be the major constituents from xanthone fraction of G. mangostana $[4,19,21-23]$. G. morrela is mainly distributed in India, Sri Lanka, and Southern Philippines. Its fruit is widely used in Northeastern India for its nutritional and medicinal properties. Despite its rich traditional uses, not much scientific study has been undertaken on this lesser known Garcinia species [24]. G. pedunculata is a semi-wild species of the Clusiaceae family and is an evergreen tree. It is endemic to the South eastern regions of Asia, such as parts of Myanmar and north eastern parts of India. Traditionally, its fruit has been used by the people of Assam as medicine to treat different types of diseases related to stomach [25]. G. xanthochymus is a medium-sized tree exuding a gummy yellow sap [26]. Its fruit is edible and have been used in bilious condition, diarrhea, and dysentery [27]. Xanthones was reported as the one of the main compounds biosynthesized by $G$. xanthochymus [28-30].

Xanthones are insoluble in water; however, these phytocompounds are soluble in other organic solvents of varying polarity, i.e., from hexane to methanol [4]. There is no report available in the literature describing the qualitative and quantitative analysis of LM, BM, and YM in fruit rinds of Garcinia species. Most of the reports available in the literature are confined to extraction and characterization of xanthones from Garcinia species using a single solvent. In addition, no information is available in the literature for simultaneous identification and quantification of LM, BM, and YM in fruit rinds of Garcinia species using a rapid ultra-high-performance liquid chromatography with photodiode array detection (UHPLCPDA) method.

Earlier, Ji et al. [21] reported quantitative and qualitative determinations of 6 xanthones (3-isomangostin, 8-desoxygartanin, gartanin, LM, 9-hydroxycalabaxanthone, and BM) in $G$. mangostana $\mathrm{L}$. by liquid chromatography-photodiode array detection (LC-PDA) and liquid chromatography-electrospray ionization mass spectrometry (LC-ESI-MS) method with a total run time of $67 \mathrm{~min}$. Walker [4] also reported a high-performance liquid chromatography (HPLC) method for the analysis of xanthones, namely, LM, 8-desoxygartanin, gartanin, BM, 3-mangostin, and 9-hydroxycalabaxanthone in mangostin fruit. Separation of 6 xanthones was achieved in a gradient elution mode with $0.1 \%$ formic acid in water and methanol. The total run time was more than $40 \mathrm{~min}$. Yodhnu et al. [31] reported a validated reversed-phase HPLC (RP-HPLC) method for the determination of LM, in mangosteen peel extract. Jing et al. [32] reported a RP-HPLC method for determination of 3 xanthones, namely, isomangostin, $\mathrm{LM}$, and $\mathrm{BM}$ in mangosteen fruit skin using a mobile phase consisting of water- $0.5 \%$ acetic acid (A) and methanol- $0.5 \%$ acetic acid (B) in the gradient elution mode. Acetonitrile and water containing $0.1 \%$ phosphoric acid (95:5) was used as the mobile phase for the HPLC determination of LM, YM, and gartanin in mangosteen fruit by Muchataridi et al. [33].

In continuation of our research work to establish the classes of compounds responsible for biological activities and to develop a liquid chromatography method for profiling of bioactive compounds in Garcinia species from India, the present investigation was carried out for a rapid and validated UHPLC-PDA method development for simultaneous identification and quantification of LM, BM, and YM in different extracts of fruits rinds of 8 Garcinia species. 
Table 1. Retention time, equation for calibration curve, linear range, LOD, and LOQ of LM, BM, and YM in the fruits rind extracts of the selected Garcinia species for the developed UHPLC-PDA method

\begin{tabular}{lccccc}
\hline Analyte & Retention time mean $(\% \mathrm{RSD})$ & Regression equation $(y=a x+b)$ & $r^{2}$ & Linearity range $(\mu \mathrm{g} / \mathrm{mL})$ & $\mathrm{LOD}(\mu \mathrm{g} / \mathrm{mL})$ \\
\hline LM & $4.68(0.03)$ & $y=24,738 x+10,275$ & 0.999 & $0.781-100$ & 0.02 \\
BM & $5.60(0.04)$ & $y=10,605 x+7902.9$ & 0.997 & $0.781-100$ & 0.06 \\
YM & $3.97(0.05)$ & $y=9018 x-2302.3$ & 0.999 & $0.781-100$ & 0.11 \\
\hline
\end{tabular}

\section{Experimental}

Materials and Reagents. Mature fresh fruits of 8 Garcinia species were collected from the different regions in India. $G$. cambogia from Indian Institute of Spices Research (IISR), Kerala, in August 2017; G. cowa from Assam Agricultural University, Jorhat, Assam, in March 2017; G. indica from Dr. Balasaheb Sawant Konkan Krishi Vidyapeeth (BSKV), Dapoli, Ratnagiri, Maharashtra, in June 2017; G. loniceroides from Pengeri, Tinsukia, Assam, in August 2017; $G$. mangostana from Vengurla, Maharashtra, in May 2017; G. morella from Bamakhepa, Barpeta, Assam, in August 2017; G. pedunculata from Ulubari, Kamrup, Assam, in March 2017; and G. xanthochymus from Ulubari, Kamrup, Assam, in March 2017 were collected. The identity of the collected fruits was confirmed by a taxonomist. Voucher specimens of the collected materials were deposited in the herbarium of the Indian Council of Agricultural Research-Directorate of Medicinal and Aromatic Plants Research (ICAR-DMAPR), Anand. LM (purity $\geq 92.0$ ) and BM (purity $\geq 96.0$ ) were purchased from ChromaDex (Mumbai, India), and YM (purity $\geq 98 \%$ ) was purchased from Sigma-Aldrich (Mumbai, India). HPLC-grade methanol (J T Bakers, Gurgaon) and formic acid (Sigma-Aldrich, Mumbai) of high purity were used. Ultrapure water was obtained from a Millipore system (Merck, Mumbai).

Fruits were compressed to remove the juice. Seeds were removed from the pulps manually. Left over fruit rinds were dried in shade, followed by oven-drying $\left(50^{\circ} \mathrm{C}, 10 \mathrm{~h}\right)$. Dried fruit rinds were made into powder using an electric grinder. The powdered rinds of Garcinia fruits were further dried in an oven $\left(50{ }^{\circ} \mathrm{C}, 2 \mathrm{~h}\right)$ in order to remove residual moisture and were extracted with hexane, chloroform, ethyl acetate, and methanol individually by a reflux method on a water bath. The extraction was carried for 6-7 h. After cooling the flasks, the extracts were filtered through Whatman Filter paper no. 1 and concentrated under reduced pressure at $50^{\circ} \mathrm{C}$ using a rotary vacuum evaporator to get crude viscous extracts. Further, the extracts were dried in a vacuum desiccator for complete removal of solvents. The solvent-free extracts were used in the present study.

Instrumentation and Chromatographic Conditions for UHPLC. Analysis was performed on a Waters ACQUITYTM UPLC H-Class (Waters, Milford, MA, USA) system equipped with a quaternary pump, an auto sampler, an ACQUITY photodiode array (PDA) detector, and Empower ${ }^{\mathrm{TM}}$ 3 software (Waters, Milford, MA, USA). An ACQUITY UPLC HSS C18 column $(2.1 \mathrm{~mm} \times 100 \mathrm{~mm}, 1.7 \mu \mathrm{m})$ (Waters, Milford, MA, USA) was used. The mobile phases consisted of 2 solvents: $0.1 \%$ formic acid in water (A) and methanol (B). Elution was carried out in the gradient mode as per the following programmings: $0-4 \mathrm{~min}, 30 \% \mathrm{~A}$; 4 $6.50 \mathrm{~min}, 5 \% \mathrm{~A} ; 6.50-6.60 \mathrm{~min}, 5 \% \mathrm{~A}$; and $6.60-9.00 \mathrm{~min}$, $30 \% \mathrm{~A}$. The flow rate of the mobile phase was $0.4 \mathrm{~mL} / \mathrm{min}$. The injection volume was $1 \mu \mathrm{L}$, and the column temperature was maintained at $40^{\circ} \mathrm{C}$. The wavelength scan range of the PDA detector was set to $190-400 \mathrm{~nm}$. The chromatograms were recorded at $254 \mathrm{~nm}$. The peaks were identified on the basis of the retention time and the PDA spectra with comparison of the standard LM, BM, and YM. Their contents in the extract samples were quantified on the basis of the peak area.

Preparation of Standards Solutions and Sample Preparation. The standard stock solutions $(1 \mathrm{mg} / \mathrm{mL})$ of the 3 reference compounds (LM, BM, and $\mathrm{YM}$ ) were prepared in HPLC-grade methanol and stored in a refrigerator at $4^{\circ} \mathrm{C}$. Working solutions of lower concentration of the 3 reference compounds were prepared by appropriate dilutions of the stock solutions in methanol. The standard solutions were filtered through a $0.22-\mu \mathrm{m}$ membrane before injection in the UHPLC system. All standard solutions were stored in a refrigerator at $4^{\circ} \mathrm{C}$.

Validation Parameters. In order to construct a calibration curve, 8 different concentrations $(0.78-100 \mu \mathrm{g} / \mathrm{mL})$ of each standard were prepared separately. The limit of detection $(\mathrm{LOD}, S / N=3$ ) and limit of quantification (LOQ, $S / N=10)$ were determined for each analyte under the acquired chromatographic conditions. The result of the regression showed that all three analytes exhibited good linearity $\left(r^{2} \geq 0.99\right)$ in a given concentration range (Table 1). Intraday and inter-day precisions and accuracy were determined by assaying 3 different concentrations $(1.56 \mu \mathrm{g} / \mathrm{mL}$, $6.25 \mu \mathrm{g} / \mathrm{mL}$, and $50 \mu \mathrm{g} / \mathrm{mL}$ ) of $\mathrm{LM}, \mathrm{BM}$, and YM. The experiment was repeated 3 times on the same day and also on 3 consecutive days (Table 2). The measurement of precision of the peak areas was expressed in terms of the RSD (\%). The accuracy was expressed as the percentage recovery (Table 3 ).

\section{Results and Discussion}

Scientific validation of the medicinal properties of natural products in terms of quantitative analysis of biologically active constituents is an important step in drug discovery. Using comparative UHPLC-PDA profiles, the identity of previously known compounds can be determined. Also, for extraction purposes, the selection of suitable solvent with polarity matching to the polarity of the compounds to be extracted plays an important role in the development of upscaling process. Although, a large number of xanthones are also reported from other Garcinia species, the quantitative analysis methods reported in the literature for xanthones are confined only to $G$. mangostana.

Extraction of Fruit Rinds of Garcinia Species. Powdered samples of the fruit rinds of the different Garcinia species were mixed with solvent (sample-solvent, 1:20), and

Table 2. Precision (\% RSD) of the developed UHPLC-PDA method at 3 different concentrations of LM, BM, and YM

\begin{tabular}{lccc}
\hline Analyte & $\begin{array}{c}\text { Concentration } \\
(\mu \mathrm{g} / \mathrm{mL})\end{array}$ & Inter-day & Intra-day \\
\cline { 3 - 4 } $\mathrm{LM}$ & 1.56 & 1.04 & 0.68 \\
& 6.25 & 1.03 & 0.79 \\
& 50 & 0.12 & 0.17 \\
$\mathrm{BM}$ & 1.56 & 0.89 & 1.21 \\
& 6.25 & 0.30 & 1.09 \\
& 50 & 0.12 & 0.17 \\
$\mathrm{YM}$ & 1.56 & 0.30 & 1.65 \\
& 6.25 & 0.19 & 0.46 \\
& 50 & 0.24 & 0.61 \\
\hline
\end{tabular}


Table 3. Recovery data for LM, BM, and YM $(n=3)$

\begin{tabular}{|c|c|c|c|}
\hline Species & Analyte & $\begin{array}{l}\text { Added concentration } \\
(\mu \mathrm{g} / \mathrm{mL})\end{array}$ & $\begin{array}{c}\text { (\%) Recovery } \\
\text { (RSD) }\end{array}$ \\
\hline G. cambogia & \multirow{8}{*}{ LM } & \multirow{8}{*}{2.5} & $76.36(0.02)$ \\
\hline G. cowa & & & $61.33(0.00)$ \\
\hline G. indica & & & $86.84(0.01)$ \\
\hline G. loniceroides & & & $48.68(0.02)$ \\
\hline G. mangostana & & & $78.97(0.03)$ \\
\hline G. morella & & & $83.74(0.01)$ \\
\hline G. pedunculata & & & $97.68(0.01)$ \\
\hline G. xanthochymus & & & $88.06(0.00)$ \\
\hline G. cambogia & \multirow{8}{*}{ LM } & \multirow{8}{*}{25} & $116.66(0.05)$ \\
\hline G. cowa & & & $211.38(0.42)$ \\
\hline G. indica & & & $188.17(0.11)$ \\
\hline G. loniceroides & & & $104.76(0.09)$ \\
\hline G. mangostana & & & $105.68(0.14)$ \\
\hline G. morella & & & $118.44(0.35)$ \\
\hline G. pedunculata & & & $115.13(0.05)$ \\
\hline G. xanthochymus & & & $116.02(0.04)$ \\
\hline G. cambogia & \multirow{8}{*}{ LM } & \multirow{8}{*}{50} & $108.62(0.35)$ \\
\hline G. cowa & & & $115.42(0.28)$ \\
\hline G. indica & & & $118.51(0.14)$ \\
\hline G. loniceroides & & & $109.91(0.33)$ \\
\hline G. mangostana & & & $111.81(0.24)$ \\
\hline G. morella & & & $109.63(0.10)$ \\
\hline G. pedunculata & & & $109.50(0.21)$ \\
\hline G. xanthochymus & & & $112.30(0.75)$ \\
\hline G. cambogia & \multirow{8}{*}{$\mathrm{BM}$} & \multirow{8}{*}{2.5} & $70.72(0.03)$ \\
\hline G. cowa & & & $51.02(0.02)$ \\
\hline G. indica & & & $82.07(0.02)$ \\
\hline G. loniceroides & & & $78.14(0.02)$ \\
\hline G. mangostana & & & $55.43(0.03)$ \\
\hline G. morella & & & $74.95(0.01)$ \\
\hline G. pedunculata & & & $94.60(0.00)$ \\
\hline G. xanthochymus & & & $54.92(0.01)$ \\
\hline G. cambogia & \multirow{8}{*}{ BM } & \multirow{8}{*}{25} & $125.93(0.01)$ \\
\hline G. cowa & & & $228.50(0.96)$ \\
\hline G. indica & & & $203.47(0.23)$ \\
\hline G. loniceroides & & & $116.19(0.11)$ \\
\hline G. mangostana & & & $112.32(0.15)$ \\
\hline G. morella & & & $127.69(0.46)$ \\
\hline G. pedunculata & & & $124.25(0.06)$ \\
\hline G. xanthochymus & & & $124.65(0.04)$ \\
\hline G. cambogia & \multirow{8}{*}{$\mathrm{BM}$} & & $114.15(0.39)$ \\
\hline G. cowa & & & $124.96(0.36)$ \\
\hline G. indica & & & $128.42(0.19)$ \\
\hline G. loniceroides & & & $112.38(0.42)$ \\
\hline G. mangostana & & 50 & $120.53(0.28)$ \\
\hline G. morella & & & $112.33(1.28)$ \\
\hline G. pedunculata & & & $115.04(0.26)$ \\
\hline G. xanthochymus & & & $117.63(0.91)$ \\
\hline G. cambogia & & & $103.44(0.01)$ \\
\hline G. cowa & & & $83.53(0.01)$ \\
\hline G. indica & & & $115.82(0.02)$ \\
\hline G. loniceroides & & & $77.03(0.01)$ \\
\hline G. mangostana & YM & 2.5 & $61.28(0.02)$ \\
\hline G. morella & & & $102.31(0.01)$ \\
\hline G. pedunculata & & & $124.82(0.01)$ \\
\hline G. xanthochymus & & & $102.30(0.02)$ \\
\hline G. cambogia & & & $134.07(0.06)$ \\
\hline G. cowa & & & $239.98(1.06)$ \\
\hline G. indica & & & $217.18(0.35)$ \\
\hline G. loniceroides & & & $120.74(0.09)$ \\
\hline G. mangostana & YM & 25 & $115.41(0.17)$ \\
\hline G. morella & & & $135.08(0.62)$ \\
\hline G. pedunculata & & & $131.37(0.10)$ \\
\hline G. xanthochymus & & & $129.29(0.08)$ \\
\hline G. cambogia & & & $115.38(0.42)$ \\
\hline G. cowa & & & $131.34(0.30)$ \\
\hline G. indica & & & $137.25(0.27)$ \\
\hline G. loniceroides & & & $116.49(0.34)$ \\
\hline G. mangostana & YM & 50 & $124.88(0.14)$ \\
\hline G. morella & & & $115.54(0.24)$ \\
\hline G. pedunculata & & & $115.64(0.36)$ \\
\hline G. xanthochymus & & & $116.62(1.13)$ \\
\hline
\end{tabular}

extraction was carried out using a refluxing method with hexane, chloroform, ethyl acetate, and methanol separately on a water bath. The extract yield is described in Table 4 .
Development and Validation of UHPLC-PDA Method. In order to achieve a good resolution and short analysis time, the chromatographic conditions were optimized. Method development was followed by method validation following the International Conference on Harmonization (ICH) guidelines $(\mathrm{ICH}, 2005)$ in terms of linearity of the calibration curves, accuracy, precision, LOD, and LOQ. The identity of the peaks in the extract samples was confirmed by spiking of $\mathrm{LM}, \mathrm{BM}$, and YM and the determination of retention time and matching PDA spectra. The unique chromophoric nature of xanthones makes them easy to identify from their UV diodearray absorption spectra [3].

The developed method was validated for the standard parameters, such as specificity, accuracy, precision, linearity, LOD, and LOQ (Table 1). Under the optimized conditions of the developed UHPLC-PDA method, the peaks of YM, LM, and $\mathrm{BM}$ were eluted at mean retention times of $3.97 \pm 0.05$, $4.68 \pm 0.03$, and $5.60 \pm 0.04 \mathrm{~min}$, respectively (Table 1). The purity of the peaks in chromatographic analysis for standard analytes, i.e., LM, BM, and YM, as well as peaks of LM, $\mathrm{BM}$, and $\mathrm{YM}$ in extract samples, were checked by comparing the peak purity angle and purity threshold values using Empower Software. For the peaks of LM, BM, and YM in standard, as well as extract samples, the purity angle was lesser than the purity threshold values, thereby confirming that eluted peaks were pure and no peak mixing was there due to co-elution.

LOD, LOQ and Linearity. LOD $(S / N=3)$ and LOQ $(S /$ $N=10$ ) were determined by following the ICH guidelines [34]. LOD value for LM, BM, and YM was $0.02,0.03$ and $0.07 \mu \mathrm{g} / \mathrm{mL}$, respectively. Similarly, the LOQ value was 0.06 , 0.11 , and $0.25 \mu \mathrm{g} / \mathrm{mL}$ for $\mathrm{LM}, \mathrm{BM}$, and YM, respectively. The linear calibration curve was constructed as a function of the concentration of the standard analytes $(x)$ versus their peak area $(y)$ for $\mathrm{LM}, \mathrm{BM}$, and YM at 8 different concentration levels $(0.78-100 \mu \mathrm{g} / \mathrm{mL})$. Linear regression analyses of the calibration curves of LM, BM, and YM provided the following equations: LM: $y=24,738 x+10,275, r^{2}=0.999$; BM: $y=10,605 x+7902.9, r^{2}=0.997$; and YM: $y=9018 x-$ 2302.3, $r^{2}=0.999$ (Table 1).

Intraday and Intermediate Precision (Reproducibility). The precision of the developed UHPLC-PDA method was verified by repeated injections of standard solutions of LM, $\mathrm{BM}$ and $\mathrm{YM}$ at 3 different concentrations. The intra-day and inter-day variations of the developed UHPLC-PDA method were evaluated by the RSD values (Table 2) obtained by estimating the corresponding responses on the same day and on 3 different days over a period of 1 week at 3 concentration levels.

Quantification of LM, BM, and YM in the Extracts of Garcinia Species. The developed and validated UHPLC-PDA method for the determination of LM, BM, and YM was employed to determine their content in different extracts. The UHPLC-PDA chromatograms of the standard mixture and the individual extracts of G. cambogia, G. cowa, G. indica, $G$. loniceroides, G. mangostana, G. morella, G. pedunculata, and G. xanthochymus fruit rinds are described in (Figures 2-10). The presence or absence of LM, BM, and YM in different extracts of various Garcinia species was confirmed by matching their retention time, spiking of the standard, and matching the PDA spectra.

The quantification of each analyte was done from the peak area of UHPLC-PDA chromatograms of the individual extracts, and the results are presented in Table 4. LM was quantified only in G. mangostana. All extracts of G. mangostana fruit rinds showed the presence of LM, and the order of its content (\%) varied in the following order: hexane 
Table 4. Contents ( $\%$ w/w) of LM, BM, and YM in the fruits rind extracts of the selected Garcinia species

\begin{tabular}{|c|c|c|c|c|c|}
\hline Species & Extract & $\%$ Yield & LM & $\mathrm{BM}$ & YM \\
\hline \multirow{4}{*}{ G. cambogia } & Hexane & 4.56 & $\mathrm{nq}$ & nd & $\mathrm{nq}$ \\
\hline & Chloroform & 10.23 & $\mathrm{nq}$ & nd & $\mathrm{nq}$ \\
\hline & Ethyl acetate & 41.87 & nd & nd & $0.02 \pm 0.01$ \\
\hline & Methanol & 39.41 & nd & nd & $\mathrm{nq}$ \\
\hline \multirow[t]{4}{*}{ G. cowa } & Hexane & 5.97 & $\mathrm{nq}$ & nd & $0.09 \pm 0.01$ \\
\hline & Chloroform & 6.69 & $\mathrm{nq}$ & nd & $0.05 \pm 0.01$ \\
\hline & Ethyl acetate & 11.25 & nd & nd & $0.03 \pm 0.01$ \\
\hline & Methanol & 49.25 & $\mathrm{nq}$ & nd & $\mathrm{nq}$ \\
\hline \multirow[t]{4}{*}{ G. indica } & Hexane & 24.32 & $\mathrm{nq}$ & nd & $\mathrm{nq}$ \\
\hline & Chloroform & 13.35 & $\mathrm{nq}$ & nd & $\mathrm{nq}$ \\
\hline & Ethyl acetate & 2.14 & $\mathrm{nq}$ & nd & $0.03 \pm 0.01$ \\
\hline & Methanol & 41.65 & nd & nd & $\mathrm{nq}$ \\
\hline \multirow[t]{4}{*}{ G. loniceroides } & Hexane & 9.09 & nd & nd & $\mathrm{nq}$ \\
\hline & Chloroform & 12.01 & nd & nd & $\mathrm{nq}$ \\
\hline & Ethyl acetate & 55.27 & nd & nd & $0.07 \pm 0.01$ \\
\hline & Methanol & 66.15 & nd & $\mathrm{nq}$ & $\mathrm{nq}$ \\
\hline \multirow[t]{4}{*}{ G. mangostana } & Hexane & 4.90 & $10.36 \pm 0.10$ & $1.17 \pm 0.01$ & $0.84 \pm 0.01$ \\
\hline & Chloroform & 7.45 & $4.88 \pm 0.01$ & $0.39 \pm 0.07$ & $1.04 \pm 0.01$ \\
\hline & Ethyl acetate & 8.95 & $3.98 \pm 0.004$ & $0.28 \pm 0.03$ & $0.63 \pm 0.04$ \\
\hline & Methanol & 36.89 & $0.044 \pm 0.002$ & $\mathrm{nq}$ & $0.15 \pm 0.01$ \\
\hline \multirow{4}{*}{ G. morella } & Hexane & 4.65 & $\mathrm{nq}$ & nd & $0.03 \pm 0.01$ \\
\hline & Chloroform & 11.77 & $\mathrm{nq}$ & nd & $0.04 \pm 0.01$ \\
\hline & Ethyl acetate & 49.46 & nd & nd & $\mathrm{nq}$ \\
\hline & Methanol & 67.70 & $\mathrm{nq}$ & nd & $0.03 \pm 0.01$ \\
\hline \multirow{4}{*}{ G. pedunculata } & Hexane & 2.94 & nd & nd & $\mathrm{nq}$ \\
\hline & Chloroform & 6.36 & nd & nd & $\mathrm{nq}$ \\
\hline & Ethyl acetate & 10.43 & nd & nd & $\mathrm{nq}$ \\
\hline & Methanol & 35.78 & nd & nd & nq \\
\hline \multirow[t]{4}{*}{ G. xanthochymus } & Hexane & 10.19 & nd & nd & $\mathrm{nq}$ \\
\hline & Chloroform & 7.56 & nd & nd & $0.03 \pm 0.001$ \\
\hline & Ethyl acetate & 12.25 & nd & nd & $\mathrm{nq}$ \\
\hline & Methanol & 39.25 & $\mathrm{nq}$ & $\mathrm{nq}$ & $\mathrm{nq}$ \\
\hline \multicolumn{6}{|c|}{$\mathrm{nq}=$ not quantified, $\mathrm{nd}=$ not detected. } \\
\hline
\end{tabular}

$(10.36 \pm 0.10)>$ chloroform $(4.88 \pm 0.01)>$ ethyl acetate $(3.98 \pm 0.004)>$ methanol $(0.044 \pm 0.002)$. LM was not quantified in the hexane and chloroform extracts of G. cambogia; the hexane, chloroform, and ethyl acetate extracts of $G$. indica; the hexane, chloroform, and methanol extracts of $G$. morella and G. cowa; and the methanol extract of G. xanthochymus. It was not detected in any extracts of $G$. loniceroides and $G$. pedunculata. BM was quantified in 3 extracts of $G$. mangostana, and its content was found in the following order: hexane $(1.17 \pm 0.01)>$ chloroform $(0.39 \pm 0.07)>$ ethyl acetate $(0.28 \pm 0.03)$; it was not quantified in the methanol extract of $G$. mangostana. BM was not quantified in the methanol extracts of $G$. loniceroides and $G$. xanthochymus. BM was also not detected in any extracts of G. cambogia, $G$. cowa, G. indica, G. morella, and G. pedunculata. Interestingly, the content of LM and BM increased as the polarity of the solvent used for the extraction decreased.

YM was quantified in the ethyl acetate extract $(0.02 \pm 0.01)$ of G. cambogia. The content of YM in G. cowa extracts was in the following order: hexane $(0.09 \pm 0.01)>$ chloroform $(0.05 \pm 0.01)>$ ethyl acetate $(0.03 \pm 0.01)$. YM was quantified in the ethyl acetate extract of $G$. indica $(0.03 \pm 0.01)$ and $G$. loniceroides $(0.07 \pm 0.01)$ only. Also, YM was quantified in all extracts from $G$. mangostana, and it varied in the following order: chloroform $(1.04 \pm 0.01)>$ hexane $(0.84 \pm 0.01)>$ ethyl acetate $(0.63 \pm 0.04)>$ methanol $(0.15 \pm 0.01)$. In G. morella, YM was quantified in 3 extracts, and their content was in the following order: chloroform $(0.04 \pm 0.01)>$ methanol $(0.03 \pm$ $0.01)=$ hexane $(0.03 \pm 0.01)$, but it was below the LOQ in the ethyl acetate extract. The content of YM in the chloroform extract of $G$. xanthochymus fruit rinds was $0.03 \pm 0.001$, but it was below the LOQ in the hexane, ethyl acetate, and methanol extracts. YM was not quantified in the hexane, chloroform, and methanol extracts of G. cambogia; methanol extracts of G. cowa; and the hexane, chloroform, and methanol extracts of $G$. indica and $G$. loniceroide. It was not quantified in the hexane, ethyl acetate, and methanol extract of G. xanthochymus; the ethyl acetate extract of G. morella; and all extracts of G. pedunculata, as its contents were below the LOQ. The above results are in agreement with earlier reports where LM and YM were found to be the major xanthones [14, 35]. Studies on the xanthones content by HPLC-PDA method are very limited. Jing et al. [32] reported the calibration curves for 3isomangotin, $\mathrm{LM}$, and $\mathrm{BM}$. The calibration curves were linear in the ranges of $21.3-213,107.7-1077$, and $10.6-106 \mu \mathrm{g} / \mathrm{mL}$, respectively. Here, the calibration curves for LM was linear in the range $0.781-100 \mu \mathrm{g} / \mathrm{mL}$, with LOD and LOQ values 0.02 and $0.06 \mu \mathrm{g} / \mathrm{mL}$, respectively. Similarly, for BM, the linearity range was $0.781-100 \mu \mathrm{g} / \mathrm{mL}$ with LOD and LOQ values of 0.03 and $0.11 \mu \mathrm{g} / \mathrm{mL}$. The linearity range for $\mathrm{YM}$ was also

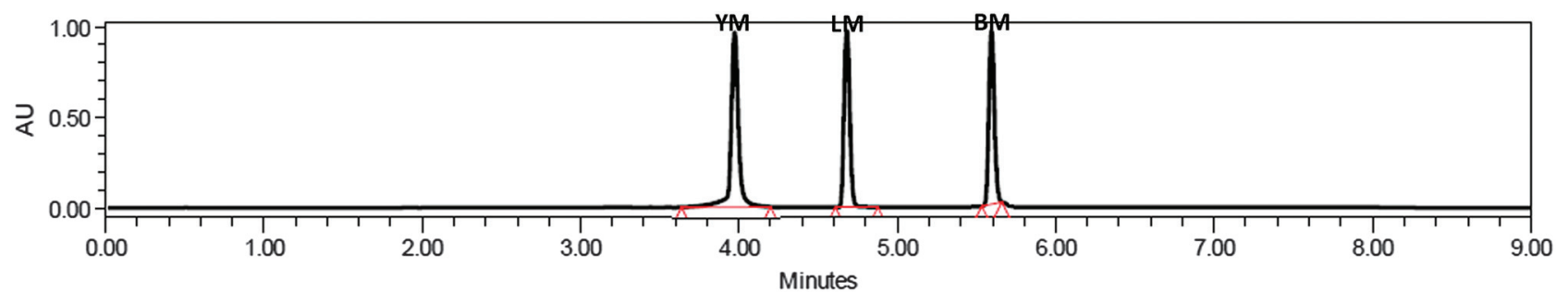

Figure 2. UHPLC-PDA chromatogram of standard mixture of YM, LM, and BM 

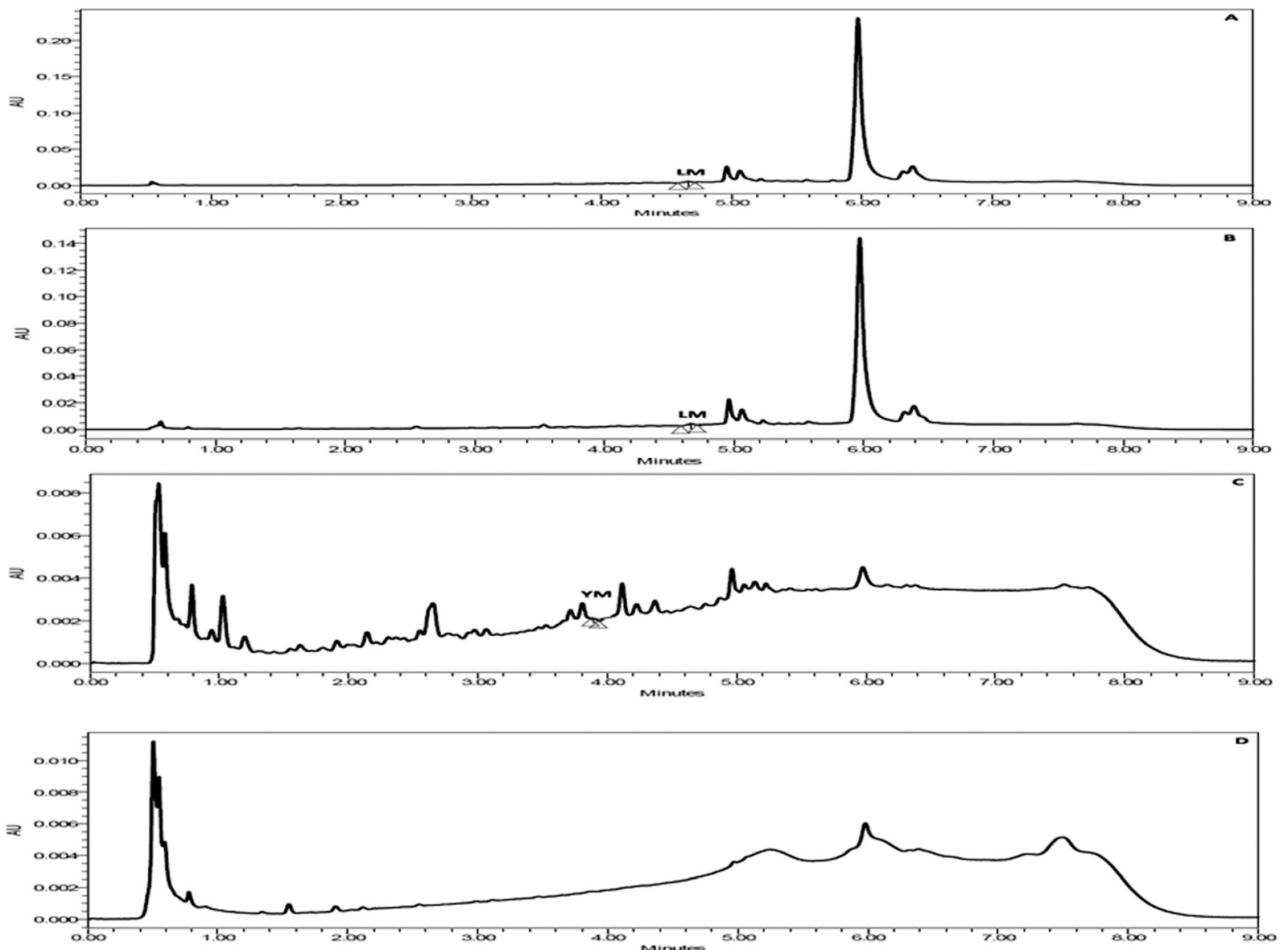

Figure 3. UHPLC-PDA chromatograms of (A) hexane, (B) chloroform, (C) ethyl acetate, and (D) methanol extracts of G. cambogia fruit rinds
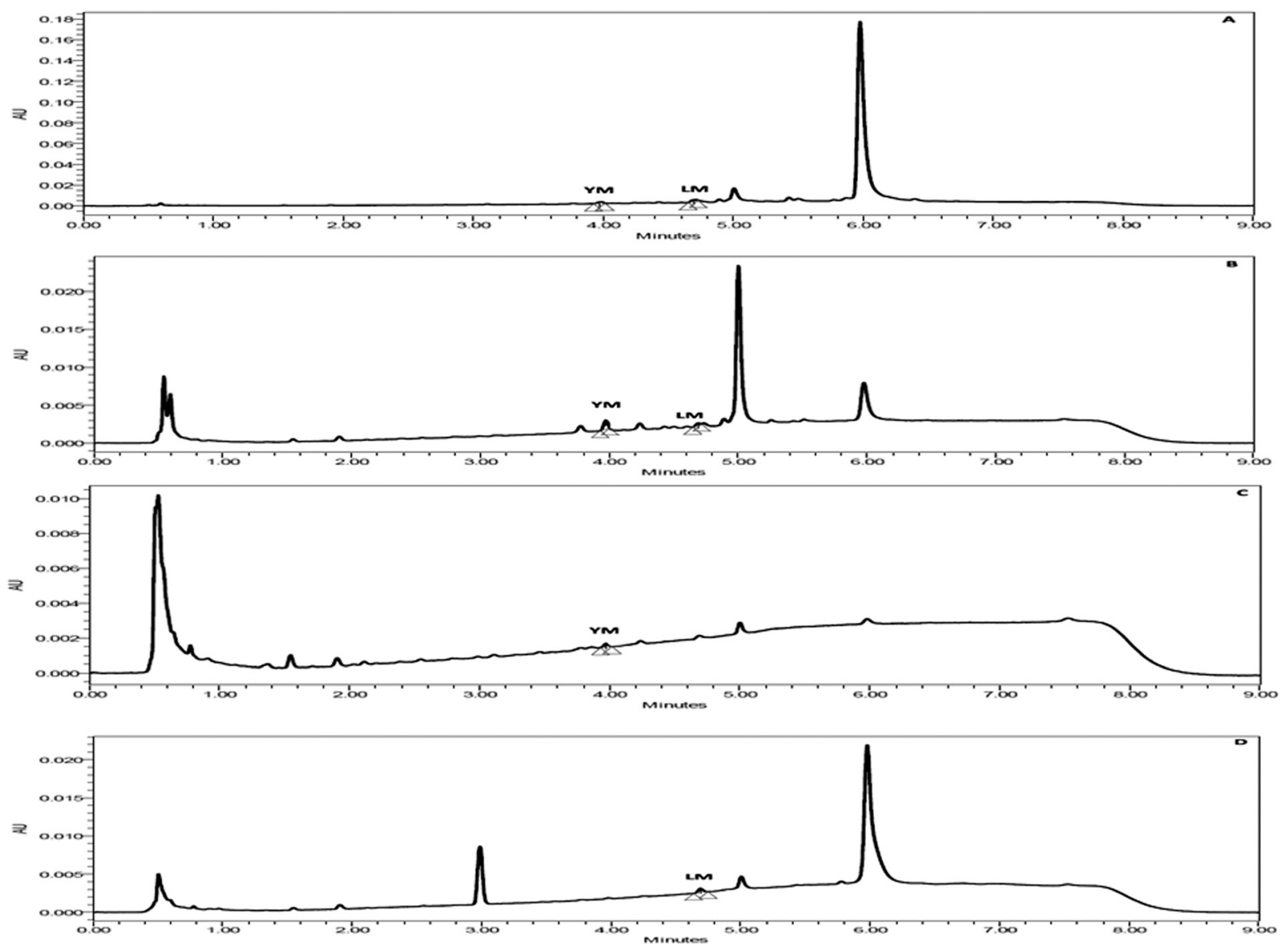

Figure 4. UHPLC-PDA chromatograms of (A) hexane, (B) chloroform, (C) ethyl acetate, and (D) methanol extracts of G. cowa fruit rinds 

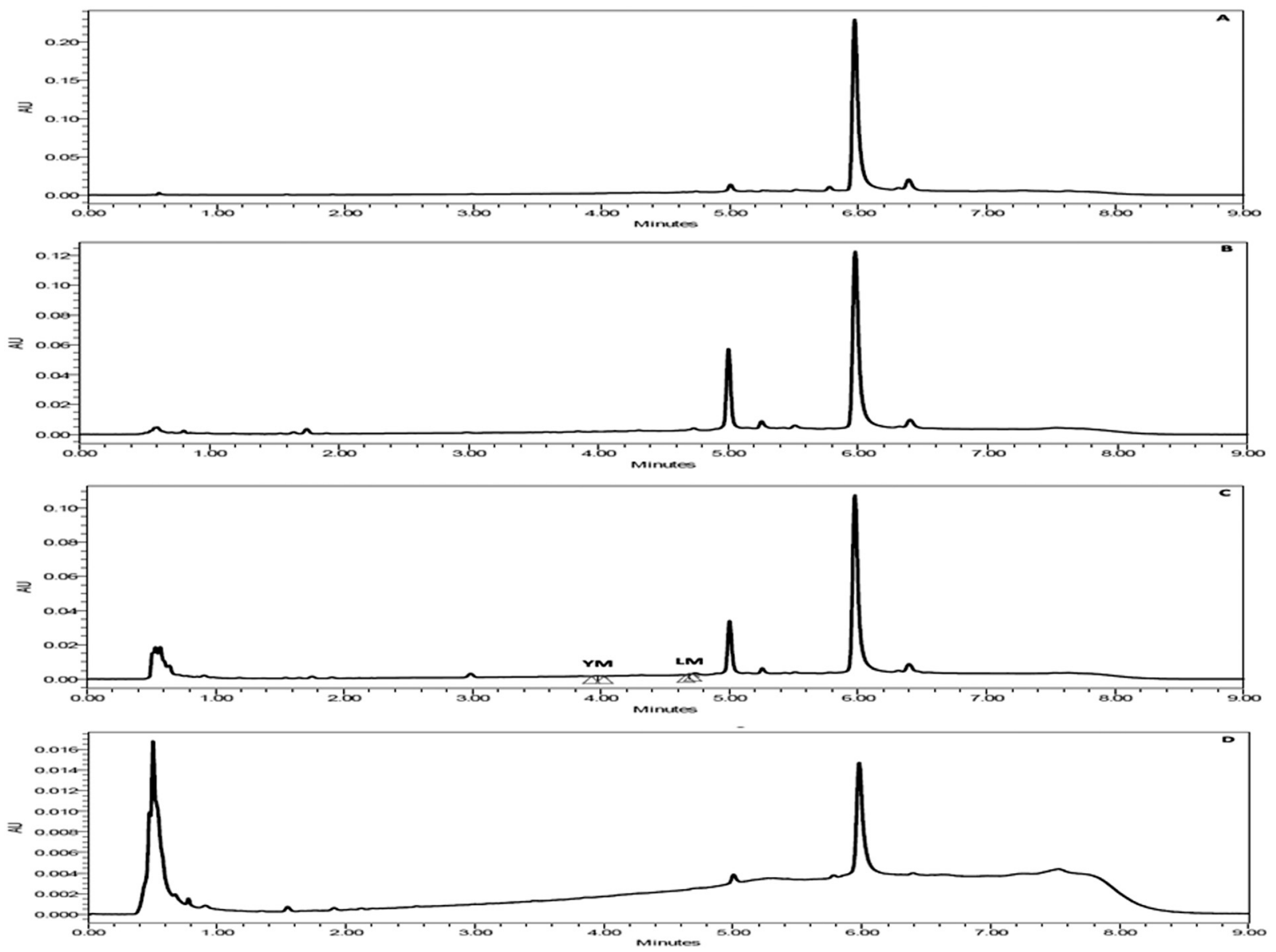

Figure 5. UHPLC-PDA chromatograms of (A) hexane, (B) chloroform, (C) ethyl acetate, and (D) methanol extracts of G. indica fruit rinds
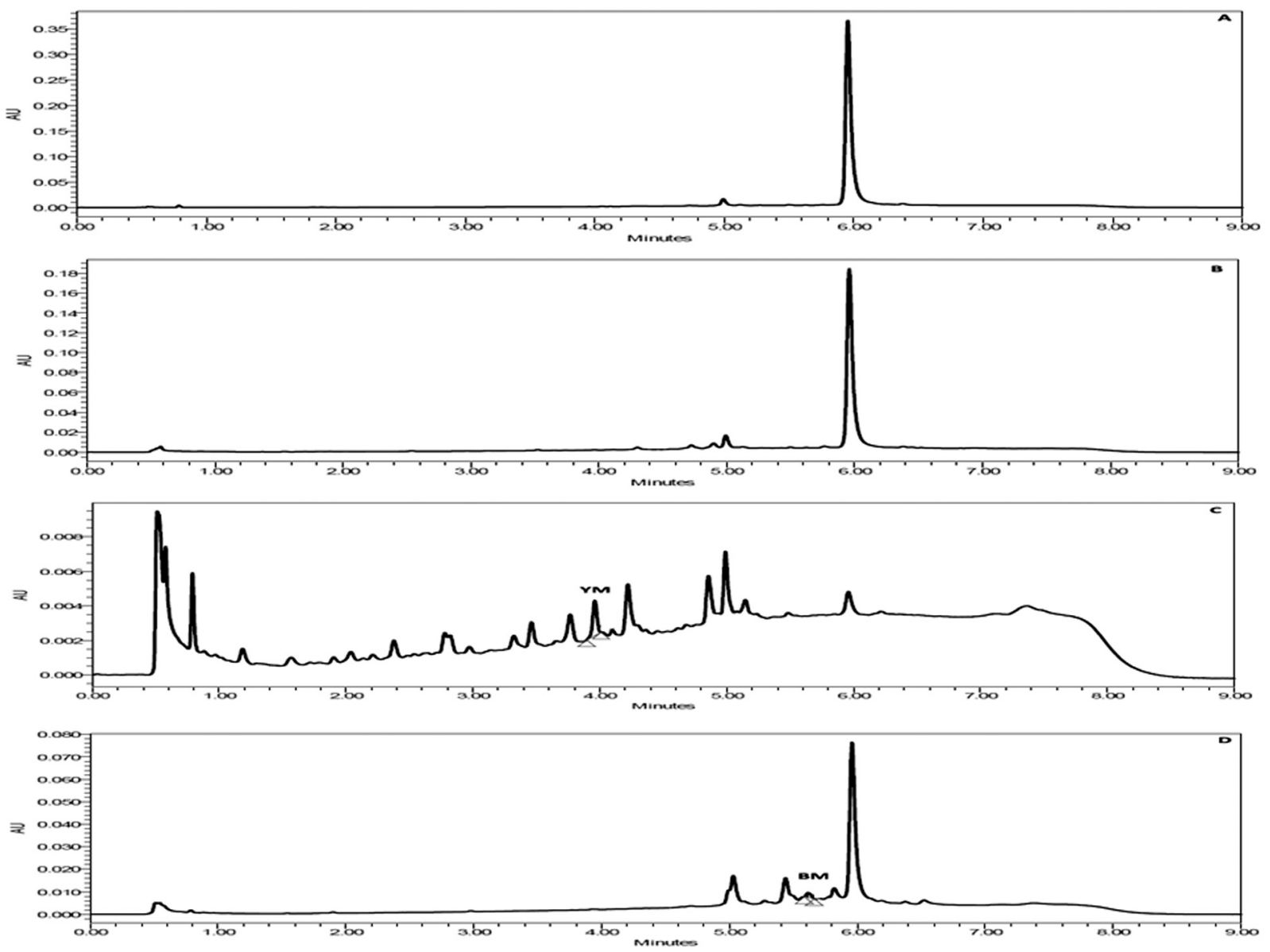

Figure 6. UHPLC-PDA chromatograms of (A) hexane, (B) chloroform, (C) ethyl acetate, and (D) methanol extracts of G. loniceroides fruit rinds 

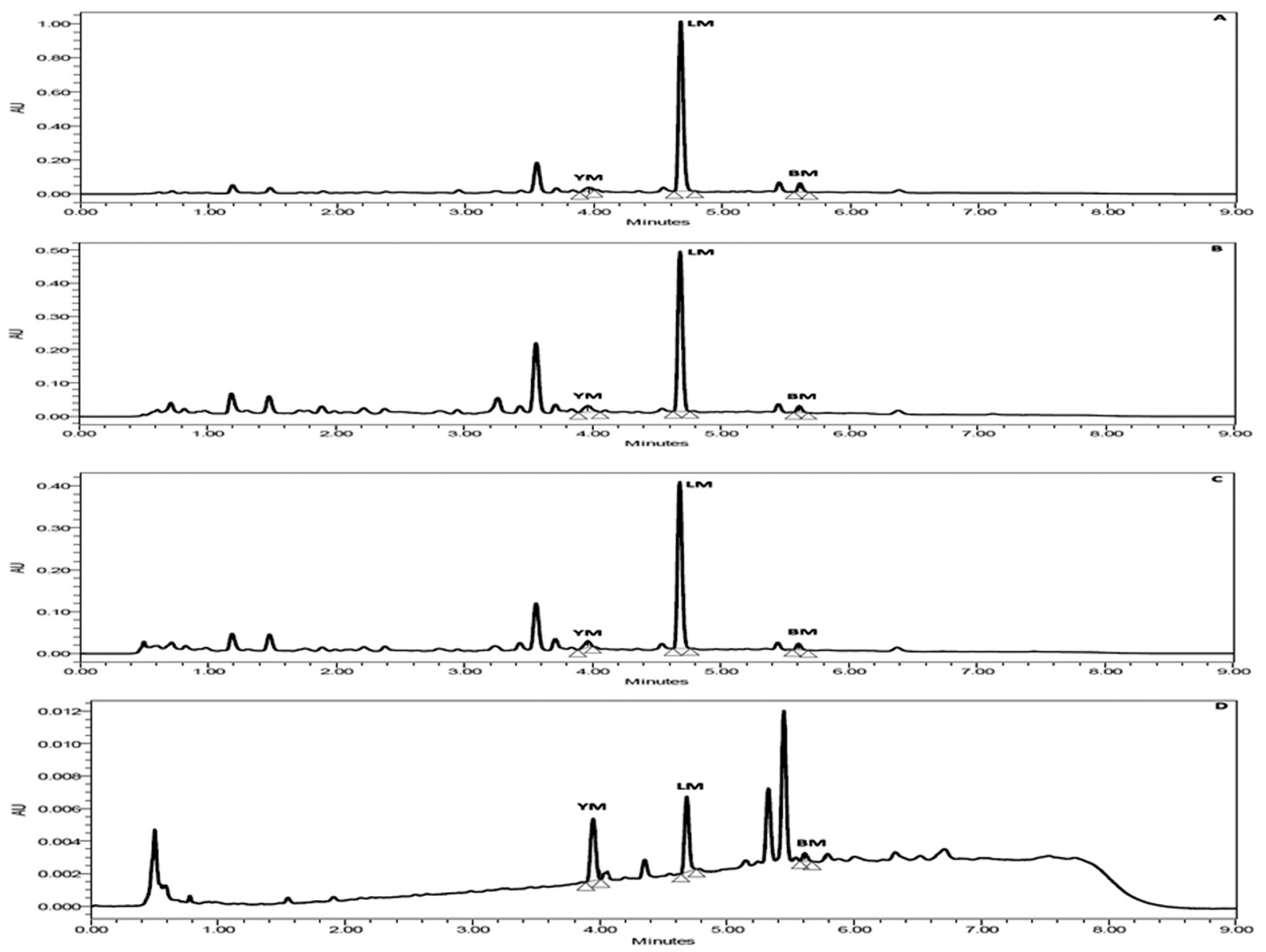

Figure 7. UHPLC-PDA chromatograms of (A) hexane, (B) chloroform, (C) ethyl acetate, and (D) methanol extracts of G. mangostana fruit rinds
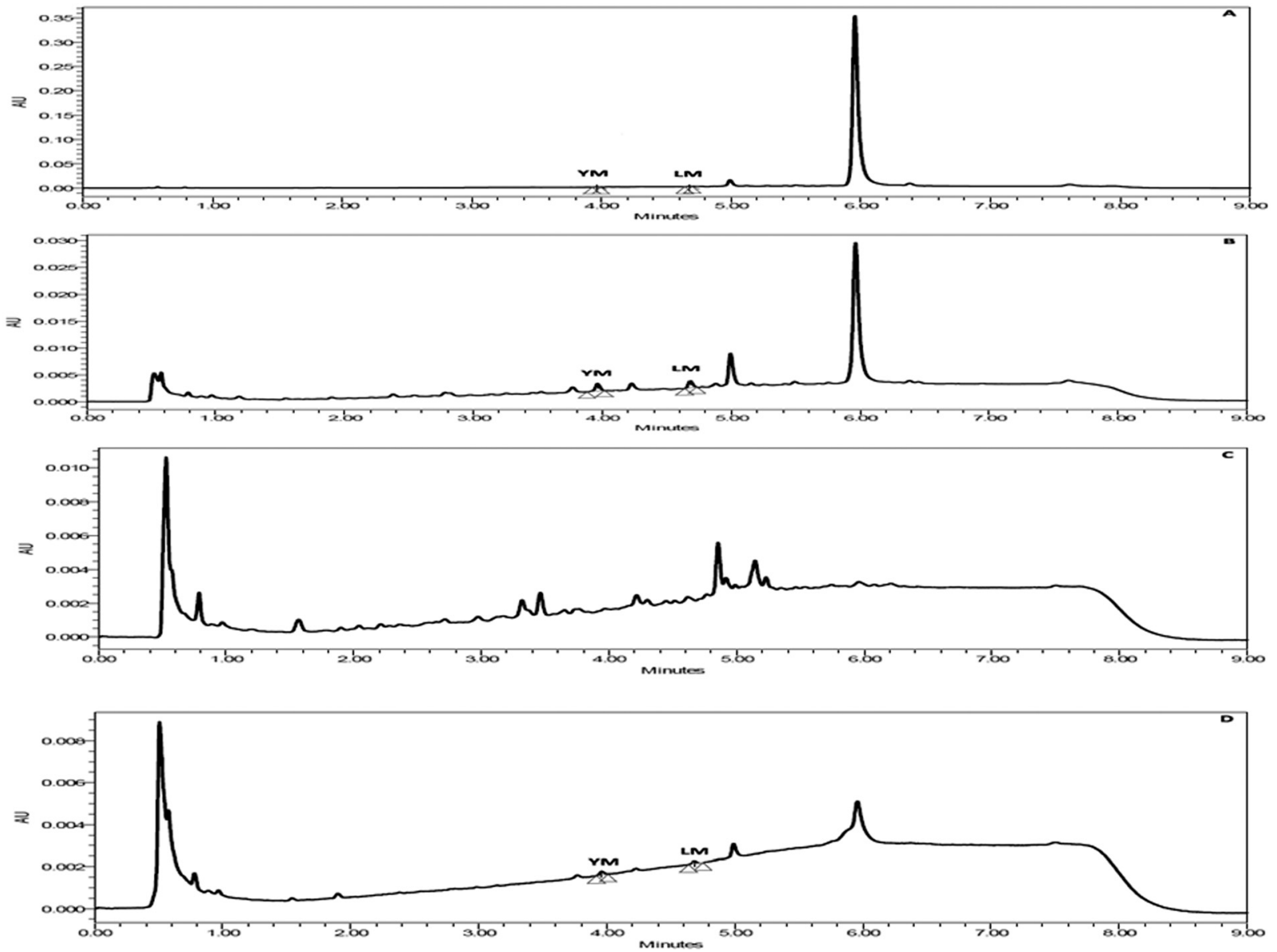

Figure 8. UHPLC-PDA chromatograms of (A) hexane, (B) chloroform, (C) ethyl acetate, and (D) methanol extracts of G. morella fruit rinds 
A.A. Kureshi et al.
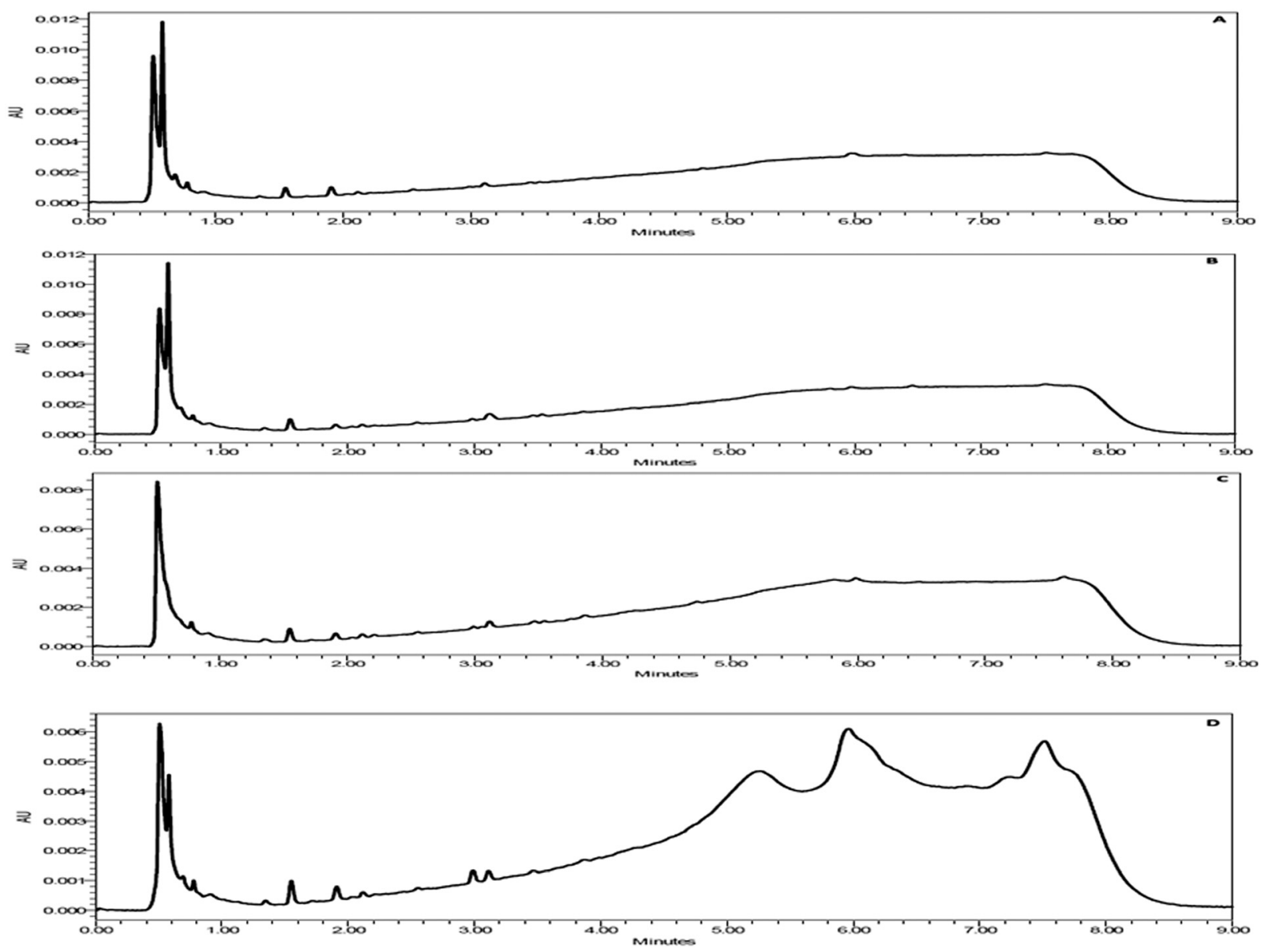

Figure 9. UHPLC-PDA chromatograms of (A) hexane, (B) chloroform, (C) ethyl acetate, and (D) methanol extracts of G. pedunculata fruit rinds
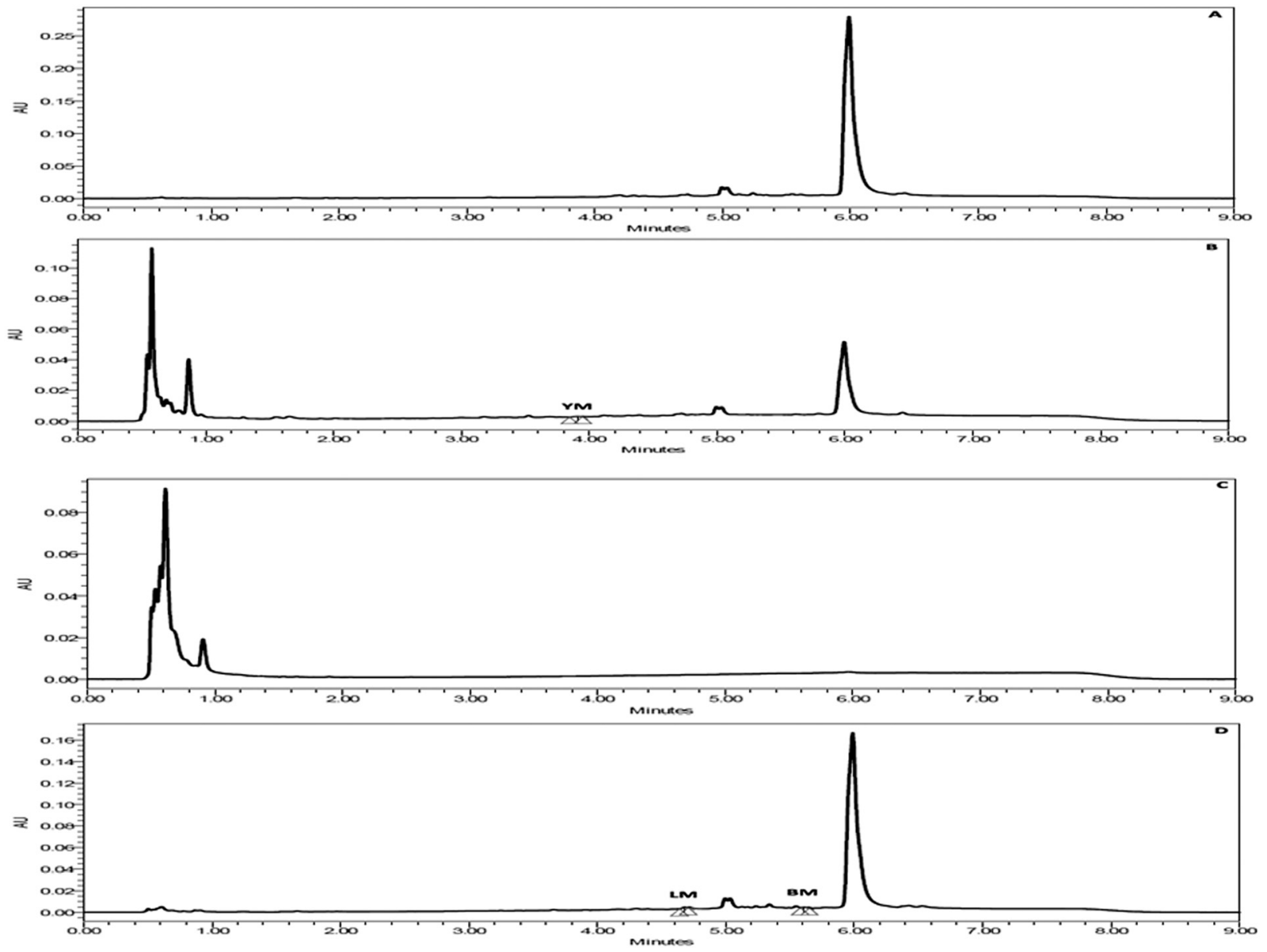

Figure 10. UHPLC-PDA chromatograms of (A) hexane, (B) chloroform, (C) ethyl acetate, and (D) methanol extracts of G. xanthochymus fruit rinds 
$0.781-100 \mu \mathrm{g} / \mathrm{mL}$ with LOD and LOQ values of 0.07 and $0.25 \mu \mathrm{g} / \mathrm{mL}$, respectively. This shows that the developed and validated UHPLC-PDA method in the present investigation was more sensitive than the method reported by Jing et al. [32].

Most of the investigations are reported for quantification of xanthones in the fruits of G. mangostana, where LM and YM were found to be the major xanthones. Pothitirat and Gritsanapan [36] reported that the contents of LM in the crude extracts and dried powder of mangosteen fruit were in the range of 8.36-10.04 and $1.84-2.47 \% \mathrm{w} / \mathrm{w}$, respectively. Walker [4] used acetone-water $(8: 2)$ for the extraction of xanthones from mangosteen fruit rinds, and 5 xanthones, namely, LM, 8-desoxygartanin, gartanin, BM, 3-mangostin, and 9-hydroxycalabaxanthone were quantified in the extracts using HPLC with UV detection (HPLC-UV) method. The content of LM and $\mathrm{BM}$ in dried fruit rinds was 5.51 and $0.170 \%$, respectively. The outcome of the present investigation showed the presence of LM, BM, and YM in other Garcinia species, and therefore, health claims associated with the fruit rinds of G. mangostana may be extended to the fruits of other Garcinia species.

\section{Conclusion}

In addition to food applications, the bioactive xanthones LM, BM, and YM also have enormous potential for pharmaceutical and cosmetic products. Supported by profiling and pattern of xanthones in selected Indian Garcinia species, the outcome of the present study could be useful in synchronizing Garcinia species, which ought to be prioritized for future domestication and advancement of their cultivation practices. Also, the developed and validated UHPLC-PDA method for profiling of LM, BM, and YM could find application in bioprospection studies of other Garcinia and related species, as well as in quality control of nutritional supplements containing Garcinia species.

\section{Abbreviations}

LM: $\alpha$-mangostin

BM: $\beta$-mangostin

YM: $\gamma$-mangostin

UHPLC-PDA: ultra-high-performance liquid chromatography-photodiode array detection

ICH: International Conference on Harmonization

Acknowledgments. The authors express sincere thanks to the ICAR for funding the present investigation in the form of a research project "ICAR-Network Project on High Value Phytochemicals/Compounds".

\section{References}

1. Magadula, J. J.; Suleimani, H. O. Tanzan. J. Health Res. 2010, 12, 1-7. 2. Fransworth, N. R.; Bunyapraphatsara, N.; Thai medicinal plants: recommended for primary health care system. Medicinal Plant Information Center, 1992.

3. Akao, Y.; Nakagawa, Y.; Inuma, M.; Nozawa, Y. Int. J. Mol. Sci. 2008, 9, 335-370.

4. Walker, E. B. J. Sep. Sci. 2007, 30, 1229-1234.

5. Moongkarndi, P.; Kosem, N.; Kaslungka, S.; Luanratana, O.; Pongpan, N.; Neungton, N.; J. Ethnopharmacol., 2004, 90, 161-166.

6. Garrity, A. R.; Morton, G. A.; Morton, G. C. Neutraceutical mangosteen composition; Official gazette of the United States patent and trade mark office patents, 1282 (1US6730333), 2004.

7. Nakatini, K.; Nakahata, N.; Arakawa, T.; Yasuda, H.; Ohizumi, Y. Biochem. Pharmacol. 2002, 63, 73-79.

8. Shan, T.; Cui, X. J.; Li, W.; Lin, W.; Lu, H.; Li, Y.; Chen, X.; Wu, T. Acta Pharmacol. Sin. 2014, 35, 1065-1073.

9. Choppa, T.; Selvaraj, C. I.; Abraham, Z. J. Food Sci. Technol. 2015, 52, 5906-5913.

10. Panthong, K.; Pongcharoen, W.; Phongpaichit, S.; Taylor, W. C. Phytochemistry, 2006, 67, 999-1004.

11. Shen, J.; Tian, Z.; Yang, J. S. Pharmazie 2007, 62, 541-549.

12. Mahabusarakam, W.; Chairek, P.; Taylor, W. C. Phytochemistry 2005, $66,1148-1153$.

13. Cheenpracha, S.; Phakhodee, W.; Ritthiwigrom, T.; Prawat, U.; Laphookhieo, S. Heterocycles 2011, 83, 1139-1144.

14. Trisuwan, K.; Ritthiwigrom, T. Arch. Pharm. Res. 2012, 35, 1733-1738.

15. Kaennakam, S.; Siripong, P.; Tip-pyang, S.; Kaennacowanols, A. C. Fitoterapia 2015, 102: 171-176.

16. Cotterill, P. J.; Scheinmann, F.; Puranik, G. S. Phytochemistry 1977, 16, $148-149$.

17. Hooker, J. D. Flora of British India, Reeve and Co. Ltd; England, 1872 ; pp. 264.

18. Obolskiy, D.; Pischel, I.; Siriwatanametanon, N.; Heinrich, M. Phytother. Res. 2009, 23, 1047-1065.

19. Jung, H. A.; Su, B. N.; Keller, W. J.; Mehta, R. G.; Kinghorn, A. D. J. Agric. Food Chem. 2006, 54, 2077-2082.

20. Peres, V.; Nagem, T. J.; Oliveira, F. F. Phytochemistry 2000, 55, 683710 .

21. Harrison, N. L. J. Phytochemistry 2002, 60, 541-548.

23. Suksamran, S.; Suwannapoch, N.; Ratananukul, P.; Aroonlerk, N.; Suksamran, S. J Nat. Prod. 2002, 65, 761-763.

24. Choudhury, B.; Kandimalla, R.; Elancheran, R; Bharali, R. Biomed. Pharmacother. 2018, 103, 562-573.

25. Sarma, R.; Devi, R. Int. J. Pharm. Sci. Invent. 2015, 4, 420-28.

26. Mabberly, D. J. The Plant Book: A Portable Dicttionary of the Higher Plants; Cambridge University, MIT Press, 1993.

27. Perry, L. M.; Metzger, J.; Medicinal Plants of East and Southeast Asia: Attributed Properties and Uses, Cambridge University, MIT Press, 1980.

28. Chen, Y.; Zhong, F.; He, H.; Hu, Y.; Zhu, D.; Yang, G. Magn. Reson. Chem. 2008, 46, 1180-1184.

29. Han, Q. B.; Qiao, C. F.; Song, J. Z.; Yang, N. Y.; Cao, X. W.; Peng, Y.; Yang, D. J.; Chen, S. L.; Xu, H. X. Chem. Biodivers. 2007, 4, 940-946.

30. Zhong, F.; Chen, Y.; Wang, P.; Feng, H.; Yang, G. Chinese J. Chem. 2009, 27, 74-80.

31. Yodhnu, S.; Sirikatitham, A.; Wattanapiromsakul, C. J. Chromatogr. Sci. 2009, 47, 185-189.

32. Jing, Y. E.; Mei-tian, X.; Xue-qin, Z.; Ya-yan, H. Chinese J. Pharm. Anal. 2012, 32, 970-972.

33. Muchataridi, M.; Puteri, N. A.; Milanda, T.; Musfiroh, I. J. Appl. Pharm. Sci. 2017, 7, 125-130.

34. ICH Harmonised Tripartite Guideline Q2 (R1), Validation of Analytical Procedures: Text and Methodology, http://www.ich.org/products/guidelines/ quality/article/quality-guidelines.html (accessed Sep. 2018).

35. Jung, H.-A.; Su, B.-N; Keller, W.J.; Mehta, R.G.; Kinghorn, A.D. J. Agric. Food Chem. 2006, 54, 2077-2082.

36. Pothitirat, W.; Gritsanapan, W. Thai J. Agric. Sci. 2009, 42, 7-12. 